\title{
Pengaruh Kompensasi dan Lingkungan Kerja terhadap Kinerja Karyawan dengan Motivasi Kerja sebagai Variabel intervening pada PT. Perkebunan Nusantara XII bagian Pengolahan Karet Kebun Kotta Blater Jember
}

\author{
(The Influence of Compensation and Work Environment to Employee's Performance with \\ Work Motivation as an Intervening Variable in PT. Perkebunan Nusantara XII Rubber \\ Processing Department Plantation Kotta Blater Jember)
}

\author{
Nurul Khoiriah*, Sri Wahyu Lelly H.S., Wiji Utami \\ Jurusan Manajemen, Fakultas Ekonomi dan Bisnis, Universitas Jember (UNEJ) \\ Jln. Kalimantan 37, Jember 68121 \\ E-mail: nurul_khoiriah30@yahoo.com
}

\begin{abstract}
Abstrak
Penelitian ini bertujuan untuk menganalisis pengaruh kompensasi dan lingkungan kerja terhadap kinerja dengan motivasi kerja sebagai variabel intervening pada PT. Perkebunan Nusantara XII bagian pengolahan karet kebun Kotta Blater Jember. Populasi dalam penelitian ini adalah semua karyawan PT Perkebunan Nusantara XII bagian pengolahan karet kebun Kotta Blater Jember. Metode sampling yang digunakan adalah sampel jenuh atau sensus dengan jumlah responden sebanyak 34 orang. Variabel yang digunakan yaitu sebanyak 4 variabel. Alat analisis yang digunakan adalah Analisis Jalur. Hasil penelitian menunjukkan bahwa : 1) Kompensasi dan lingkungan kerja berpengaruh signifikan terhadap motivasi kerja di PTPN XII Kebun Kotta Blater Jember; 2) Kompensasi dan lingkungan kerja berpengaruh signifikan terhadap kinerja karyawan di PTPN XII Kebun Kotta Blater Jember, dan; 3) Motivasi kerja berpengaruh signifikan terhadap kinerja karyawan di PTPN XII Kebun Kotta Blater Jember.
\end{abstract}

Kata Kunci: kompensasi, lingkungan kerja, motivasi kerja kinerja karyawan.

\begin{abstract}
This research entitled "The Influence of Compensation and Work Environment to employee's Performance with work motivation as an intervening variable in PT. Perkebunan Nusantara XII Rubber Processing Department Plantation Kotta Blater Jember Jember ". This study aimed to analyze the influence of compensation and work environment to employee's performance with work motivation as an intervening variable in PT. Perkebunan Nusantara XII rubber processing department plantation Kotta Blater Jember. The population in this research were all employees of PT Perkebunan Nusantara XII rubber processing department plantation Kotta Blater Jember. The sampling method used is saturated sample or census with the number of respondents as many as 34 people. Variables used as many as 4 variables. The analysis tool used is Path Analysis. The results showed that: 1) Compensation and work environment have a significant influence on work motivation in PTPN XII Plantation Kotta Blater Jember; 2) Compensation and work environment have a significant influence on the employee's Performance in PTPN XII Plantation Kotta Blater Jember, and; 3) Motivation significant influence on the employee's Performance in PTPN XII Plantation Kotta Blater Jember.
\end{abstract}

Keywords: Compensation, Work Environment, Work Motivation and Employee Performance.

\section{Pendahuluan}

Dalam sebuah perusahaan maupun organisasi, sumber daya manusia merupakan salah satu faktor yang sangat penting karena memberi kontribusi untuk tercapainya tujuan perusahaan dan sumber daya manusia merupakan salah satu penggerak utama atas kelancaran jalannya kegiatan sebuah perusahaan.

Pemberian kompensasi pada karyawan merupakan hal yang perlu diperhatikan oleh perusahaan maupun organisasi, karena dengan adanya pemberian kompensasi yang tinggi tentu akan mempengaruhi karyawan untuk termotivasi dalam bekerja dan akan berdampak pada kinerja karyawan. Saydam (2000:267), menyatakan bahwa kompensasi yang memadai merupakan alat motivasi yang paling ampuh bagi perusahaan untuk mendorong para karyawan bekerja lebih baik.

Lingkungan kerja sebagai salah faktor yang dapat mempengaruhi kinerja karyawan juga harus diperhatikan oleh perusahaan. Hal ini dikarenakan kondisi lingkungan kerja yang baik akan memberikan motivasi kerja bagi para karyawan dalam menyelesaikan beban tugasnya. Lingkungan kerja yang kurang baik dapat menuntut tenaga kerja dan waktu yang lebih banyak dan tidak mendukung diperolehnya rancangan sistem kerja yang efisien (Sedarmayanti, 2001:12). Apabila lingkungan kerja baik maka hal tersebut dapat memacu timbulnya rasa puas dalam diri karyawan yang pada akhirnya dapat memberikan pengaruh positif terhadap kinerja karyawan, begitu sebaliknya, apabila lingkungan kerja buruk maka karyawan tidak akan mempunyai kepuasan dalam bekerja.

Kompensasi berupa gaji yang diberikan oleh PT. Perkebunan Nusantara XII dirasa masih kurang cukup untuk memenuhi kebutuhan sehari-hari para karyawan. Hal ini sangat berbanding terbalik dengan pekerjaan yang dilakukan oleh para karyawan. Selain itu, Kondisi lingkungan kerja yang kurang memadai dan bau tidak sedap dari getah karet yang

* Corresponding author 
akan diolah sangat menganggu proses kerja karyawan. Sehingga hal tersebut berpengaruh terhadap kinerja karyawan PT. Perkebunan Nusantara XII.

Rumusan masalah dalam penelitian ini adalah a. Apakah kompensasi berpengaruh terhadap motivasi kerja karyawan PTPN XII bagian Pengolahan Karet Kebun Kotta Blater Jember? b. Apakah lingkungan kerja berpengaruh terhadap motivasi kerja karyawan PTPN XII bagian Pengolahan Karet Kebun Kotta Blater Jember? c. Apakah kompensasi berpengaruh terhadap kinerja karyawan PTPN XII bagian Pengolahan Karet Kebun Kotta Blater Jember? d. Apakah lingkungan kerja berpengaruh terhadap kinerja karyawan PTPN XII bagian Pengolahan Karet Kebun Kotta Blater Jember? e. Apakah motivasi kerja berpengaruh terhadap kinerja karyawan PTPN XII bagian Pengolahan Karet Kebun Kotta Blater Jember?

Penelitian ini bertujuan a. Untuk mengetahui dan menganalisis pengaruh kompensasi terhadap motivasi kerja karyawan PTPN XII bagian Pengolahan Karet Kebun Kotta Blater Jember. b. Untuk mengetahui dan menganalisis pengaruh lingkungan kerja terhadap motivasi kerja karyawan PTPN XII bagian Pengolahan Karet Kebun Kotta Blater Jember. c. Untuk mengetahui dan menganalisis pengaruh kompensasi terhadap kinerja karyawan PTPN XII bagian Pengolahan Karet Kebun Kotta Blater Jember. d. Untuk mengetahui dan menganalisis pengaruh lingkungan kerja terhadap kinerja karyawan PTPN XII bagian Pengolahan Karet Kebun Kotta Blater Jember. e. Untuk mengetahui dan menganalisis pengaruh motivasi kerja terhadap kinerja karyawan PTPN XII bagian Pengolahan Karet Kebun Kotta Blater Jember.

\section{Metode}

\section{Rancangan atau Desain Penelitian}

Rancangan penelitian ini menggunakan pendekatan kualitatif yang dikuantitatifkan dan merupakan penelitian explanatory research. Explanatory research merupakan penelitian yang digunakan untuk menjelaskan hubungan kausal antara variabel-variabel melalui pengujian hipotesis.

\section{Jenis dan Sumber Data}

Data yang digunakan dalam penelitian ini adalah data primer yang diperoleh langsung dari responden (objek penelitian) berupa jawaban responden atas pernyataan yang diajukan dalam kuisioner. Data sekunder dalam penelitian ini adalah data yang diperoleh dari arsip atau laporan yang tersedia tentang beberapa hal yang berkaitan dengan PTPN XII bagian pengolahan karet kebun Kotta Blater Jember.

\section{Populasi dan Sampel}

Populasi dari penelitian ini adalah seluruh karyawan tetap PTPN XII bagian pengolahan karet kebun Kotta Blater Jember yakni berjumlah 34 orang. Karena metode pengambilan sampel dalam penelitian ini dilakukan dengan teknik sampling jenuh atau sensus maka jumlah sampel yang digunakan dalam penelitian ini yakni sebanyak 34 responden yang sudah memenuhi tingkat kelayakan jumlah sampel.

\section{Metode Analisis Data}

Alat analisis yang digunakan dalam penelitian ini adalah analisis jalur atau path analysis. Analisis jalur atau path analysis merupakan bagian dari analisis regresi yang digunakan untuk menganalisis hubungan kausal antar variabel dimana variabel-variabel bebas mempengaruhi variabel tergantung, baik secara langsung maupun tidak langsung, melalui satu atau lebih variabel perantara (Sarwono, 2006: 147). Analisis jalur atau path analysis digunakan untuk mengetahui Pengaruh Kompensasi dan Lingkungan Kerja terhadap Kinerja Karyawan dengan Motivasi Kerja sebagai Variabel Intervening pada PT. Perkebunan Nusantara XII bagian Pengolahan Karet Kotta Blater Jember.

\section{Hasil dan Pembahasan}

\section{Hasil}

Karakteristik Responden

Responden dalam penelitian ini digolongkan berdasarkan umur, jenis kelamin, lama bekerja dan pendidikan.

Tabel 1. Tingkat Umur Responden

\begin{tabular}{lll}
\hline Umur & Jumlah (Orang) & Presentase \\
\hline 25-35 tahun & 7 & $20,58 \%$ \\
36-45 tahun & 18 & $28.12 \%$ \\
diatas 45 tahun & 9 & $14.06 \%$ \\
& & \\
\hline Total & 34 & $100,00 \%$ \\
\hline
\end{tabular}

Sumber : data primer diolah, 2016

Tabel 2. Jenis Kelamin Responden

\begin{tabular}{lll}
\hline Jenis Kelamin & Jumlah (Orang) & Presentase \\
\hline Laki-laki & 30 & $88,23 \%$ \\
Perempuan & 4 & $11,76 \%$ \\
\hline Total & 34 & $100,00 \%$ \\
\hline
\end{tabular}

Sumber : data primer diolah, 2016

Tabel 3. Lama Bekerja Responden

\begin{tabular}{lll}
\hline Lama Bekerja & Jumlah (Orang) & Presentase \\
\hline$<10$ tahun & 3 & $8,82 \%$ \\
$10-11$ tahun & 23 & $67.64 \%$ \\
$>15$ tahun & 8 & $23.52 \%$ \\
& & \\
\hline Total & 34 & $100,00 \%$ \\
\hline
\end{tabular}

Sumber : data primer diolah, 2016

Tabel 4. Tingkat Pendidikan Responden

\begin{tabular}{lll}
\hline Tingkat Pendidikan & Jumlah (Orang) & Presentase \\
\hline Sederajat & 22 & $64,71 \%$ \\
Diploma & 5 & $14.71 \%$ \\
Strata & 7 & $20.58 \%$ \\
& & \\
\hline Total & 34 & $100,00 \%$ \\
\hline
\end{tabular}

Sumber : data primer diolah, 2016

\section{Uji Normalitas Model}

Berdasarkan hasil uji normalitas model dapat diketahui bahwa variabel Gaya Kepemimpinan Transformasional (X1) memiliki nilai probabilitas atau signifikansi sebesar 0,087 , variabel Budaya Organisasi (X2) memiliki nilai probabilitas atau signifikansi sebesar 0,126, Lingkungan Kerja (X3) memiliki nilai probabilitas atau signifikansi sebesar 0,142 , variabel Disiplin Kerja (Z) memiliki nilai probabilitas atau signifikansi sebesar 0,200, variabel Kinerja Karyawan (Y) 
memiliki nilai probabilitas atau signifikansi sebesar 0,200 Nilai tersebut lebih besar dari 0,05. Sehingga, dapat dinyatakan bahwa data dalam penelitian ini semua variabel berdistribusi normal.

\section{Uji Instrumen}

\section{a. Uji Validitas}

Berdasarkan uji validitas dapat diketahui bahwa korelasi antara masing-masing indikator variabel Gaya Kepemimpinan Transformasional (X1), Budaya Organisasi (X2), Lingkungan Kerja (X3), Disiplin Kerja (Z) dan Kinerja Karyawan (Y) menunjukkan hasil yang signifikan dengan nilaiRh $_{\text {asil }}>\mathrm{Rt}_{\text {abel }}$ dan $\mathrm{Sig}<0,05$. Hal ini dapat disimpulkan bahwa semua item pertanyaan variabel Gaya Kepemimpinan Transformasional (X1), Budaya Organisasi (X2), Lingkungan Kerja (X3), Disiplin Kerja (Z) dan Kinerja Karyawan (Y) dinyatakan valid.

\section{b. Uji Reliabilitas}

Berdasarkan hasil uji reliabilitas pada instrumen variabel Gaya Kepemimpinan Transformasional (X1) dengan nilai Cronbach's Alpha atau ralpha sebesar 0,809. Hasil pengujian reliabilitas pada instrumen variabel Budaya Organisasi (X2) dengan nilai Cronbach's Alpha atau ralpha sebesar 0,758. Hasil pengujian reliabilitas pada instrumen variabel Lingkungan Kerja (X3) dengan nilai Cronbach's Alpha atau r alpha sebesar 0,760. Hasil pengujian reliabilitas pada instrumen variabel Disiplin Kerja (Z) dengan nilai Cronbach's Alpha atau r alpha sebesar 0,773. Hasil pengujian reliabilitas pada instrumen variabel Kinerja Karyawan (Y) dengan nilai Cronbach's Alpha atau r alpha sebesar 0,753. Hal ini membuktikan instrumen penelitian berupa kuesioner ini telah reliabel karena $r$ alpha yang bernilai lebih besar dari 0,60 .

\section{Analisis Jalur (Path Analysis)}

Tabel 5. Hasil Path Analysis Variabel

\begin{tabular}{|c|c|c|c|c|c|c|c|c|}
\hline \multicolumn{2}{|c|}{ Unstanderdized } & \multirow{2}{*}{\multicolumn{2}{|c|}{$t_{\text {hitung }}$}} & \multirow[b]{2}{*}{$t_{\text {tabel }}$} & \multirow[b]{2}{*}{ Sig. } & \multirow{2}{*}{\multicolumn{2}{|c|}{$a$}} & \multirow{2}{*}{$\begin{array}{c}\text { Keteranga } \\
\mathrm{n}\end{array}$} \\
\hline Jalur & $\begin{array}{c}\text { Beta } \\
(\beta)\end{array}$ & & & & & & & \\
\hline $\mathrm{x}_{1} \rightarrow \mathrm{Z}$ & 0,529 & 4,686 & $>$ & 2,045 & 0,000 & $<$ & 0,05 & Signifikan \\
\hline $\mathrm{x}_{2} \rightarrow \mathrm{Z}$ & 0,387 & 3,469 & $>$ & 2,045 & 0,001 & $<$ & 0,05 & Signifikan \\
\hline $\mathrm{X}_{1} \rightarrow \mathrm{Y}$ & 0,424 & 3,178 & $>$ & 2,045 & 0,003 & $<$ & 0,05 & Signifikan \\
\hline $\mathrm{X}_{2} \rightarrow \mathrm{Y}$ & 0,320 & 2,436 & $>$ & 2,045 & 0,021 & $<$ & 0,05 & Signifikan \\
\hline $\mathrm{Z} \rightarrow \mathrm{Y}$ & 0,679 & 6,682 & $>$ & 2,045 & 0,000 & $<$ & 0,05 & Signifikan \\
\hline$\varepsilon 1$ & 0,306 & - & & - & - & & - & - \\
\hline 22 & 0,415 & - & & - & - & & - & - \\
\hline
\end{tabular}

sumber: data primer diolah, 2016

Berdasarkan Tabel 5, Untuk menganalisis jalur pertama dapat dijelaskan bahwa antara Kompensasi (X1) dengan Motivasi Kerja (Z) memiliki pengaruh yang signifikan. Hal tersebut dapat diketahui dengan hasil nilai signifikan yaitu 0,000 lebih kecil dari $\alpha=0,05$. Jalur kedua antara Lingkungan Kerja (X2) dengan Motivasi Kerja ( $Z$ ) memiliki pengaruh yang signifikan yaitu sebesar 0,001 lebih kecil dari $\alpha=0,05$. Jalur ketiga antara Kompensasi (X1) dengan Kinerja Karyawan (Y) memiliki pengaruh yang signifikan sebesar 0,003 yaitu lebih kecil dari $\alpha=0,05$. Jalur keempat antara Lingkungan
Kerja (X2) dengan Kinerja Karyawan (Y) memiliki pengaruh signifikan sebesar 0,021 yaitu lebih kecil dari $\alpha=0,05$. Jalur kelima antara Motivasi Kerja (Z) dengan Kinerja Karyawan (Y) memiliki pengaruh signifikan sebesar 0,000 yaitu lebih kecil dari $\alpha=0,05$

\section{Uji Asumsi Klasik}

\section{a. Uji Multikolinearitas}

Berdasarkan hasil analisis Collinearity Statistics dapat diketahui bahwa model tidak terjadi multikolinieritas. Hal tersebut ditandai dengan nilai VIF dari masing-masing variabel kurang dari 10.

\section{b. Uji Heteroskedastisitas}

Berdasarkan hasil uji heteroskedastisitas diketahui bahwa tebaran data tidak membentuk garis tertentu atau tidak terdapat pola yang jelas serta titik-titik menyebar diatas dan dibawah angka nol pada sumbu Y, maka dari hasil tersebut diketahui bahwa tidak terjadi heterokesdatisitas dari persamaan yang diuji.

\section{c. Uji Normalitas Model}

Berdasarkan hasil uji normalitas model yang didapatkan yakni data terdistribusi dengan normal, karena data terlihat menyebar mengikuti garis diagonal.

\section{Uji Hipotesis}

Uji t

Berdasarkan Uji $\mathrm{t}$ hipotesis menunjukkan hasil sebagai berikut:

\section{a. Pengaruh kompensasi terhadap motivasi kerja}

Variabel kompensasi terhadap motivasi karyawan diperoleh nilai $\mathrm{t}_{\text {hitung }}>\mathrm{t}_{\text {tabel }}(4,686>2,045)$ dan signifikasi $0,000<$ 0,05. Maka Ho ditolak dan Ha diterima, yang berarti ada pengaruh kompensasi terhadap motivasi karyawan PTPN XII Kebun Kotta Blater Jember. $t_{\text {hitung }}$ positif, maka jika ada peningkatan pada variabel kompensasi akan meningkatkan motivasi karyawan.

\section{b. Pengaruh lingkungan kerja terhadap motivasi kerja}

Variabel lingkungan kerja terhadap motivasi karyawan diperoleh nilai $t_{\text {hitung }}>t_{\text {tabel }}(3,469>2,045)$ dan signifikasi $0,001<0,05$. Maka Ho ditolak dan Ha diterima, yang berarti ada pengaruh lingkungan kerja terhadap motivasi karyawan

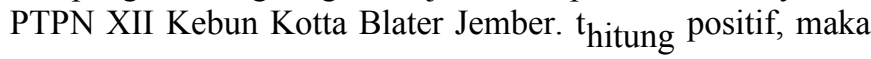
jika ada peningkatan pada variabel lingkungan kerja akan meningkatkan motivasi karyawan.

\section{c. Pengaruh kompensasi terhadap kinerja karyawan}

Variabel kompensasi terhadap kinerja karyawan diperoleh nilai $\mathrm{t}_{\text {hitung }}>\mathrm{t}_{\text {tabel }}(3,178>2,045)$ dan signifikasi $0,003<$ 0,05. Maka Ho ditolak dan Ha diterima, yang berarti ada pengaruh kompensasi terhadap kinerja karyawan PTPN XII Kebun Kotta Blater Jember. $t_{\text {hitung }}$ positif, maka jika ada peningkatan pada variabel kompensasi akan meningkatkan kinerja karyawan.

\section{d. Pengaruh lingkungan kerja terhadap kinerja karyawan}


Variabel lingkungan kerja terhadap kinerja karyawan diperoleh nilai $t_{\text {hitung }}>t_{\text {tabel }}(2,436>2,045)$ dan signifikasi $0,021<0,05$. Maka Ho ditolak dan Ha diterima, yang berarti ada pengaruh lingkungan kerja terhadap kinerja karyawan PTPN XII Kebun Kotta Blater Jember. $t_{\text {hitung }}$ positif, maka jika ada peningkatan pada variabel lingkungan kerja akan meningkatkan kinerja karyawan.

\section{e. Pengaruh motivasi kerja terhadap kinerja karyawan}

Variabel motivasi karyawan terhadap kinerja karyawan diperoleh nilai $t_{\text {hitung }}>t_{\text {tabel }}(6,682>2,045)$ dan signifikasi $0,000<0,05$. Maka Ho ditolak dan Ha diterima, yang berarti ada pengaruh motivasi karyawan terhadap kinerja karyawan PTPN XII Kebun Kotta Blater Jember. $t_{\text {hitung }}$ positif, maka jika ada peningkatan pada variabel motivasi karyawan akan meningkatkan kinerja karyawan.

\section{Pembahasan}

\section{Pengaruh Kompensasi terhadap Motivasi Kerja}

Penelitian menunjukkan bahwa kompensasi yang diberikan kepada karyawan PTPN XII Kebun Kotta Blater Jember, membuktikan bahwa pengaruh langsung variabel kompensasi terhadap motivasi karyawan PTPN XII Kebun Kotta Blater Jember adalah sebesar 52,9\%. Kompensasi yang diberikan kepada karyawan PTPN XII Kebun Kotta Blater Jember dengan memberikan gaji yang dapat mencukupi kebutuhan hidup dari karyawannya, pemberian bonus kerja yang diberikan karena karyawan telah berkerja sesuai dan memberikan hasil yang baik dalam berkerja, pemberian jaminan asuransi dan tunjangan didalam berkerja telah menjadikan karyawan lebih terdorong dalam berkerja secara maksimal untuk dapat memberikan yang terbaik bagi perusahaan PTPN XII Kebun Kotta Blater. Karyawan yang ada pada bagian produksi berkerja secara sesuai dan lebih fokus dalam berkerja, karyawan melakukan pengukuran bahan - bahan campuran produksi karet secara baik dan melakukan pengoprasian mesin lebih sesuai dengan SOP yang telah diterapkan di PTPN XII Kebun Kotta Blater.

Hasil penelitian ini sesuai dengan yang dilakukan oleh Ramadhani (2013), yang menyatakan bahwa kompensasi akan dapat meningkatkan motivasi kerja karyawannya didalam sebuah perusahaan karena dengan kompensasi yang sesuai dengan beban kerja, tanggungjawab serta kebutuhan maka lebih memberikan dorongan kepada karyawan untuk dapat berkerja lebih baik.

Hasil penelitian ini juga sesuai dengan pendapat yang diajukan oleh Simamora (2004:450), menyatakan bahwa organisasi memberdayakan kompensasi untuk memotivasi para karyawannya. Oleh karena itu, apabila kebutuhan dari karyawan sudah terpenuhi dengan pemberian kompensasi yang tepat, maka karyawan akan termotivasi melakukan pekerjaannya secara optimal. Dengan demikian maka perusahaan akan mencapai tujuan yang diinginkan. Hasibuan (2002:118), menambahkan bahwa kompensasi adalah semua pendapatan yang berbentuk uang, barang langsung atau tidak langsung yang diterima karyawan sebagai imbalan atau jasa yang diberikan kepada perusahaan. Setiap orang yang melakukan pekerjaan, pasti mempunyai maksud dan tujuan tertentu. Begitu juga karyawan yang bekerja pada suatu perusahaan pasti mengharapkan imbalan atau sumbangsih tenaganya terhadap perusahaan.

\section{Pengaruh Lingkungan Kerja terhadap Motivasi Kerja}

Penelitian menunjukkan bahwa lingkungan kerja yang ada di PTPN XII Kebun Kotta Blater Jember, membuktikan bahwa pengaruh langsung variabel lingkungan kerja terhadap motivasi karyawan PTPN XII Kebun Kotta Blater Jember adalah sebesar 38,7\%. Lingkungan kerja yang ada di PTPN XII Kebun Kotta Blater Jember penerangan yang sesuai, ventilasi udara yang baik, lingkungan kerja yang tidak terlalu bising, keamanan akan perlindungan kerja dalam melaksanakan tugas dan tanggungjawab juga terjadi, maka karyawan yang ada dapat lebih berkerja ekstra untuk dapat menyelesaikan tugas dan tanggungjawab kerjanya dibagian produksi secara lebih baik. Karyawan dibagian produksi merasa nyaman dan sesuai serta lebih termotivasi dengan keadaan lingkungan kerjanya, karyawan dapat berkerjasama dengan rekan kerjanya dibagian produksi untuk melakukan perencanaan, pengolahan bahan baku, dan lebih mengoptimalkan kinerja mesin serta lain sebagainya.

Hasil penelitian ini sesuai dengan yang dilakukan oleh Ansaruddin (2012), yang menyatakan bahwa lingkungan kerja akan mampu mempengaruhi motivasi kerja karyawannya didalam sebuah lingkungan kerjanya, karenanya karyawan akan lebih merasa sesuai didalam berkerja dan terdorong didalam melakukan banyak hal yang sesuai tugas dan tanggungjawabnya didalam perusahaan.

Hasil penelitian ini juga sesuai dengan pendapat yang diajukan oleh Nitisemito (2002:184), menyatakan bahwa lingkungan kerja adalah sesuatu yang ada disekitar para pekerja dan yang dapat mempengaruhi dirinya dalam menjalankan tugas-tugas yang dibebankan, untuk dapat meningkatkan motivasi karyawan maka diperlukan adanya suatu kondisi sekitar lingkungan kerja yang nyaman, aman, bergairah dan sikap saling terbuka antar pegawai didalamnya. Karena dengan motivasi kerja yang tinggi karyawan dapat melaksanakan tugas yang dibebankan kepadanya dengan baik sehingga berdampak pada sikap percaya pada perusahaan. Mangkunegara (2006:94), menambahkan bahwa motivasi kerja sebagai kondisi yang berpengaruh membangkitkan, mengarahkan dan memelihara perilaku yang berhubungan dengan lingkungan kerja. Oleh karena itu, perusahaan harus memperhatikan lingkungan kerja yang ada di perusahaan. Hal ini dikarenakan kondisi lingkungan kerja yang baik akan memberikan motivasi kerja bagi para karyawan dalam menyelesaikan beban tugasnya.

\section{Pengaruh Kompensasi terhadap Kinerja Karyawan}

Penelitian menunjukkan bahwa kompensasi yang diberikan kepada karyawan PTPN XII Kebun Kotta Blater Jember, membuktikan bahwa pengaruh langsung variabel kompensasi terhadap kinerja karyawan PTPN XII Kebun Kotta Blater Jember adalah sebesar 42,4\%. Kompensasi yang diberikan dilingkungan PTPN XII Kebun Kotta Blater Jember dengan adanya gaji yang diterima telah memenuhi kebutuhan bagi karyawannya, karyawan juga merasa aman dengan adanya asuransi kerja yang diberikan oleh perusahaan, serta pemberian tunjangan kerja yang diberikan perusahaan kepada karyawannya, telah menjadikan karyawan dapat lebih berusaha untuk menyelesaikan tugas dengan penuh rasa tanggung jawab untuk mencapai hasil yang maksimal dan 
lebih dapat mengutamakan kerja sama dengan rekan kerja dalam menyelesaikan pekerjaan yang telah ditugaskan oleh atasannya. Kompensasi yang diberikan akan sangat beguna sekali dalam menunjang kinerja secara individu maupun kerjasama yang dilakukan didalam bagian produksi karet yang ada di PTPN XII Kebun Kotta Blater Jember.

Hasil penelitian ini sesuai dengan yang dilakukan oleh Afriansyah (2014), yang menyatakan bahwa kompensasi akan memberikan peningkatan terhadap kinerja karyawan dalam suatu lingkungan kerjanya, karena dengan adanya kompensasi yang diberikan secara sesuai oleh perusahaan maka karyawan dapat lebih tenang dalam berkerja, dapat lebih berkerjasama secara aktif serta memberikan hasil yang lebih baik dalam berkerja.

Hasil penelitian ini juga sesuai dengan pendapat yang diajukan oleh Sentono (1999), kinerja karyawan akan baik bila digaji atau diberi upah sesuai perjanjian. Dengan demikian, pemberian kompensasi yang baik kepada karyawan sangat mempengaruhi kinerja karyawan. Mahmudi (2005:179) menambahkan bahwa kinerja tidak dapat dilepaskan dari kompensasi, kompensasi merupakan salah satu elemen penting dalam kinerja karyawan. Secara umum kompensasi merupakan sesuatu yang diterima karyawan atas balas jasa kerja mereka. Simamora (2004), juga menambahkan bahwa kompensasi dalam bentuk financial adalah penting bagi karyawan, sebab dengan kompensasi ini mereka dapat memenuhi kebutuhannya secara langsung, terutama kebutuhan fisiologisnya. Dalam bentuk nonfinansial juga sangat penting bagi karyawan terutama untuk pengembangan karir mereka.

\section{Pengaruh Lingkungan Kerja terhadap Kinerja Karyawan}

Penelitian menunjukkan bahwa lingkungan kerja yang ada di PTPN XII Kebun Kotta Blater Jember, membuktikan bahwa pengaruh langsung variabel lingkungan kerja terhadap kinerja karyawan PTPN XII Kebun Kotta Blater Jember adalah sebesar 32,0\%. Lingkungan kerja di PTPN XII Kebun Kotta Blater Jember dengan adanya jaminan keamanan kerja sebagai perlindungan kerja kepada karyawannya dalam melakukan tugas yang telah diperintahkan oleh atasannya atau menjalankan perintah sesuai dengan SOP yang berlaku di PTPN XII Kebun Kotta Blater, adanya penerangan yang ada diruang kerja yang mencukupi kebutuhan karyawan dalam berkerja dan lingkungan kerja yang terjamin dari limbah karet yang tidak sedap, telah menjadikan karyawan dapat lebih bersungguh - sungguh dalam berkerja sehingga pekerjaan yang ada dan dihasilkan dapat sesuai dengan target yang telah ditetapkan PTPN XII Kebun Kotta Blater. Lingkungan kerja yang sesuai dengan kebutuhan kerja dari karyawan bagian produksi akan lebih memberikan kesungguhan kepada karyawan dalam berkerja dibagian produksi PTPN XII Kebun Kotta Blater.

Hasil penelitian ini sesuai dengan yang dilakukan oleh Prasetyo (2013), yang menyatakan bahwa lingkungan kerja yang relatif sesuai dengan kebutuhan kerja dari karyawannya akan dapat lebih memberikan rasa nyaman dan semangat didalam berkerja, karyawan yang berkerjapun akan dapat menyelesaikan pekerjaannya sesuai dengan tugas dan tanggungjawab yang telah diberikan oleh atasannya.
Hasil penelitian ini juga sesuai dengan pendapat yang diajukan oleh Sedarmayanti (2002:136), menyatakan bahwa Kondisi lingkungan kerja dikatakan baik atau sesuai apabila manusia dapat melaksanakan kegiatan secara optimal, sehat, aman dan nyaman. Kesesuaian lingkungan kerja dapat dilihat akibatnya dalam jangka waktu yang lama. Lingkungan kerja yang kurang baik dapat menuntut tenaga kerja dan waktu yang lebih banyak dan tidak mendukung diperolehnya rancangan sistem kerja yang efisien. Menurut Mangkunegara (2004:68), lingkungan kerja mempunyai hubungan yang sangat erat terhadap kinerja karyawan, motif berprestasi yang perlu dimiliki oleh karyawan harus ditumbuhkan dari dalam diri sendiri dan dari lingkungan kerja, karena motif berprestasi yang ditumbuhkan dari dalam diri sendiri akan membentuk suatu kekuatan diri dan jika situasi lingkungan kerja turut menunjang maka pencapaian kinerja akan lebih mudah.

\section{Pengaruh Motivasi Kerja terhadap Kinerja Karyawan}

Penelitian menunjukkan bahwa kinerja karyawan yang ada di PTPN XII Kebun Kotta Blater Jember, membuktikan bahwa pengaruh langsung variabel motivasi karyawan terhadap kinerja karyawan PTPN XII Kebun Kotta Blater Jember adalah sebesar 67,9\%. Motivasi kerja karyawan di PTPN XII Kebun Kotta Blater Jember dengan karyawan yang telah diberikan jaminan asuransi keselamatan dalam bekerja di perusahaan, karyawan juga merasa senang karena rekan kerja lainnya di perusahaan ini dapat menerima sebagai rekan kerja yang baik, dan gaji yang diberikan juga cukup untuk memenuhi kebutuhan karyawan dan keluarganya, sehingga karyawan yang berkerja dapat lebih berusaha dalam menyelesaikan pekerjaan yang sesuai dengan target yang telah ditetapkan perusahaan dalam produksinya, serta karyawan juga dapat lebih berusaha dalam menyelesaikan tugas dan tanggungjawabnya untuk mencapai hasil yang maksimal dan sesuai dengan harapan perusahaannya.

Hasil penelitian ini sesuai dengan yang dilakukan oleh Farlen (2011) dan Prasetyo (2013), yang menyatakan bahwa motivasi karyawan akan memberikan dampak yang baik terhadap kinerja karyawannya, dengan motivasi kerja karyawan dalam berkerja maka karyawan dapat lebih maksimal dalam mengerjakan tugas dan tanggungjawabnya di perusahaan.

Hasil penelitian ini juga sesuai dengan pendapat yang diajukan oleh Buchari (2000:103), menyatakan bahwa dalam suatu perushaaan atau organisasi ada motivasi yang diberikan kepada karyawan berupa material, akan tetapi masih belum cukup mempengaruhi kinerja karyawan. Sehubungan dengan hal itu, dalam meningkatkan kinerja karyawan hal yang perlu dilakukan oleh perusahaan berupa penciptaan kondisi-kondisi yang mendorong motivasi karyawan. Kondisi yang diberikan harus sesuai dengan keahlian dan tingkat pendidikan yang dimiliki karyawan, yaitu penciptaan kondisi yang berbentuk insentif nonmaterial seperti pembinaan karir karyawan. Dengan adanya jenjang karir inilah perusahaan menghadapkan adanya suatu reaksi karyawannya agar dapat meningkatkan prestasi kerja dan disiplin yang tinggi sehingga diharapkan dapat menunjang kinerja karyawan., faktor yang motivasi merupakan hal yang perlu dikembangkan pada diri karyawan agar dapat memperkuat usaha dalam mencapai tujuan yang diharapkan perusahaan. Motivasi dan 
kemampuan kerja merupakan syarat pokok yang istimewa bagi manusia yang berpengaruh terhadap kinerja karyawan.

\section{Simpulan}

BBerdasarkan hasil analisis data maka dapat disimpulkan halhal sebagai berikut: (a). Kompensasi berpengaruh signifikan terhadap motivasi karyawan di PTPN XII Kebun Kotta Blater Jember. Hal ini membuktikan bahwa kompensasi yang sesuai dengan kebutuhan dan mencukupi dari karyawannya maka akan meningkatkan kinerja karyawannya. (b). Lingkungan kerja berpengaruh signifikan terhadap motivasi karyawan di PTPN XII Kebun Kotta Blater Jember. Hal ini membuktikan bahwa lingkungan kerja yang sesuai dan nyaman untuk sebuah proses kerja maka akan meningkatkan kinerja karyawannya. (c). Kompensasi berpengaruh signifikan terhadap kinerja karyawan di PTPN XII Kebun Kotta Blater Jember. Hal ini membuktikan bahwa kompensasi yang relatif sesuai dengan beban kerja dan tanggungjawab kerja karyawan di perusahaan maka akan meningkatkan kinerja karyawan. (d). Lingkungan kerja berpengaruh signifikan terhadap kinerja karyawan di PTPN XII Kebun Kotta Blater Jember. Hal ini membuktikan bahwa lingkungan kerja memberikan jaminan kepada karyawannya dalam berkerja maka akan meningkatkan kinerja karyawan. (e). Motivasi kerja berpengaruh signifikan terhadap kinerja karyawan di PTPN XII Kebun Kotta Blater Jember. Hal ini membuktikan bahwa motivasi kerja karyawan yang didasari atas dasar kesesuaian didalam berkerja maka akan meningkatkan kinerja karyawan.

\section{Referensi}

Hasibuan, Malayu S.P. 2002. Manajemen Sumber Daya Manusia. Cetakan Keenam belas. Jakarta: PT. Bumi Aksara.

Sarwono, J. 2006. Analisis Data Penelitian Menggunakan SPSS. Yogyakarta: Andi.

Saydam, Gaouzali. 2000. Manajemen Sumber Daya Manusia (Suatu Pendekatan Mikro). Jakarta: Djambatan.

Sedarmayanti. 2009. Sumber Daya Manusia dan Produktifitas Kerja. Jakarta: Mandar Maju.

Simamora, Henry. 2004. Manajemen Sumber Daya Manusia. Yogyakarta. Penerbit STIE YKPN.

Afriansyah, Ardy. 2014. Pengaruh Kompensasi dan Konflik Kerja terhadap Kinerja Karyawan (study pada Kantor PT. Pos Indonesia (persero) Mail Processing Center Semarang. Skripsi. Universitas Diponegoro.

Ansaruddin, I.R. 2012. Pengaruh Stres Kerja dan Lingkungan Kerja terhadap Motivasi Kerja bagian Frontliner PT Bank Mandiri (persero) Tbk Cabang Makassar Kartini dan Cabang Makassar Slamet Riyadi. Skripsi. Universitas Hasanudin.

Farlen, Frans. 2011. Pengaruh Motivasi Kerja dan Kemampuan Kerja terhadap Kinerja Karyawan. Skripsi

Ramadhani, Ayu A. 2013. Pengaruh Kompensasi terhadap Motivasi Kerja di PT. Pos Indonesia (persero) Bandung. Skripsi. Universitas Pendidikan Indonesia. 